Eixo Temático: Desenvolvimento de Estratégias Didáticas

\title{
ET-07-006 \\ ESTRATÉGIAS DIDÁTICAS LÚDICAS PARA O ENSINO DE BIOLOGIA CELULAR: TIPOS, ESTRUTURA, FUNÇÕES E A EVOLUÇÃO DAS CÉLULAS
}

\author{
André dos Santos ${ }^{1,4}$, Wed’lla Thaís Barbosa da Silva ${ }^{1,2,3}$, Amália Cristine Medeiros Ferreira ${ }^{5}$ \\ ${ }^{1}$ Graduado em Ciências Biológicas (Licenciatura), Departamento de Ciências Biológicas - \\ Faculdade de Formação de Professores da Mata Sul - FAMASUL, Palmares-PE \\ ${ }^{2}$ Especialista em Ensino de Biologia, Centro de Ciências Biológicas - FAINTVISA, Vitória-PE. \\ ${ }^{3}$ Especialista em Psicopedagogia Institucional e Clínica, Departamento de Pedagogia - \\ Faculdade Anchieta, Recife-PE. \\ ${ }^{4}$ Professor da Rede Estadual de Ensino de Pernambuco. \\ ${ }^{5}$ Doutora em Bioquímica e Fisiologia, Departamento de Bioquímica, Universidade Federal de \\ Pernambuco - UFPE - Recife, Pernambuco.
}

http://dx.doi.org/10.21472/congrebio2016.et-07-006

\section{RESUMO}

O presente trabalho tem como objetivo, apresentar estratégias didáticas e lúdicas no ensino de Biologia Celular, uma vez que os alunos do Ensino Médio possuem dificuldades em acompanhar os conteúdos abordados no próprio livro didático, pois a complexidade metodológica e a linguagem literária levam muitas vezes ao aluno a não ter um aprendizado mais objetivo e eficiente, causando-lhes uma "falha de aprendizado" no sentido de acompanhar e contextualizar esses assuntos do conhecimento científico. Foi visto a necessidade de implantar estratégias, que visam contribuir para construção de conhecimentos, a partir da contextualização dos conteúdos aprendidos de maneira lúdica, enfatizando de uma forma abrangente, tipos, estruturas, funções e evolução das células. Para tal, foram construídos os jogos de citologia e paródias musicais, dessa forma o professor expõem de uma forma dinâmica e criativa as estruturas biológicas, diferenças entre procariontes e eucariontes, de uma forma que não seja cansativa e desmotivadora, deixando de lado o método tradicional de ensino e tornando o aprendizado mais produtivo e proporcionando melhor fixação dos conteúdos. Os resultados foram obtidos a partir da metodologia aplicada, através de jogos com palavras cruzadas e músicas parodiadas, nas turmas do $1^{\circ}$ ano do Ensino Médio da EREM Frei Epifânio no Município de São Joaquim do Monte-PE. No primeiro momento foram utilizadas nas turmas as palavras cruzadas, e logo após teve a música parodiada ambas voltadas para os conteúdos de biologia celular, a partir disso foi percebido uma melhor interação dos alunos, por si tornar um momento mais agradável e motivador. Com essas ações pode-se perceber que a criação de estratégias, como jogos (cruzadinhas) e músicas, desenvolvem diferentes capacidades no aluno que contribuem para a aprendizagem, ampliando uma rede de significados construtivos.

Palavras-chave: Biologia Celular; Método Tradicional; Jogos.

\section{INTRODUÇÃO}

O estudo de Biologia Celular é considerado um dos ramos mais complexos da Biologia. As dificuldades encontradas por professores na construção do processo de aprendizagem podem ser atribuídas não somente à complexidade dos temas, mas também aos recursos didáticos utilizados nas aulas de biologia no ensino médio, onde o meio mais utilizado é a aula expositiva dialogada, e o uso do próprio livro didático. Santana et al. (2006) destacam que rever os conteúdos de ciências dentro de uma postura interdisciplinar significa rever aquilo que 
determina sua essência, sua finalidade maior. Para tanto, estratégias metodológicas que visam auxiliar no aprendizado do educando, tais como: oficinas pedagógicas, atividades lúdicas, pedagogia de projetos, aulas práticas e de campo, jogos, músicas, entre outros, têm sido estudadas.

Como lembra Teixeira (2006), os conceitos científicos são como redes de conhecimentos que em conjunto explicam algo, cabendo ao professor investigar se os conceitos empregados pelos alunos incluem a explicação causal que ele substantiva, ou se é apenas memorização de termos empregados sem clareza da teoria na qual o conceito está emerso.

É necessário investigar propostas metodológicas diferenciadas para as aulas de biologia celular, a fim de facilitar o processo de aprendizagem do aluno e despertar o interesse pelos conteúdos. Fortuna (2011) argumenta e defende com veemência o poder da ludicidade no campo educativo, por ser motivadora de aprendizagens e produzir momentos de leveza na sala de aula.

Quando o professor trabalha em sala de aula de maneira contextualizada e dinâmica, a inserção do lúdico propicia um ambiente favorável para a construção do aprendizado. O ensino de biologia celular pode ser auxiliado com o uso de vários recursos, como jogos e paródias musicais que envolvam o conteúdo abordado. Hoje é comum a presença de música nas salas de aulas do ensino médio como meio alternativo de facilitar a aprendizagem do discente. Nardelli (2000) informa que "será de encantos a escola que, com frequência, se valer dos cantos, pois eles despertam a emoção, e esta desencadeia toda uma sequência de sensações agradáveis a ela, que vão fazer com que o processo de aprendizagem lhe seja mais fácil e significativo”. Os jogos por sua vez são atividades lúdicas no processo de ensino. "A escola que pretende ser facilitadora deverá fazer uso dos jogos, eles mexem com todos os sentidos do indivíduo, exigem sua atenção e obediência às regras estabelecidas”. Essas atividades que incluem jogos são excelentes instrumentos para motivação da aprendizagem do aluno.

Os jogos de citologia, por exemplo, facilitam o processo de ensino, e além de tornar a aula dinâmica, podem fazer com que o aluno passe a gostar dos conteúdos. As palavras cruzadas também são ótimas opções como bagagem educativa para tornar mais amplo esse processo educativo.

A capacidade de pensar melhora na qualidade de raciocínio e estímulo a curiosidade são benefícios educativos esperados com o uso dos métodos lúdicos. Desse modo, desde quando o Ministério da Educação (MEC) resolveu introduzir a revista "coquetel” nas escolas, esse tipo de jogo passou a facilitar e instigar melhorias significativas no processo de aprendizagem auxiliando de forma motivadora os alunos.

$\mathrm{O}$ aluno pode ser o próprio protagonista no processo de ensino e aprendizagem como construtores de seu conhecimento e não como assimiladores de conceitos básicos e teorias que venham envolver a biologia celular.

Muitos profissionais apresentam dificuldades em inserir jogos de maneira lúdica e educativa nas aulas de citologia, e preferem seguir o método tradicional. Às vezes devido a não compreensão de que o jogo em si possui uma finalidade básica, e outros acabam interpretando que os mesmos sejam apenas uma brincadeira sem nenhum propósito. Kishimoto (1999) coloca que um jogo com finalidades educativas desenvolve, simultaneamente, duas funções: a lúdica que diz respeito ao prazer e diversão proporcionados pelo jogo; e a educativa que é a função de ensinar algo por meio de sua utilização e ressalta que o equilíbrio entre estas é imprescindível para motivar o aprendizado voluntário.

As paródias musicais não deixam de ser outro tipo de ferramenta lúdica de grande importância para a aprendizagem, já que as mesmas despertam a curiosidade dos alunos pela música e as letras fazem com que os mesmos fixem melhor o assunto que é abordado. Segundo Uriarte (2004), ela gera conhecimentos e tem especial significado porque opera com força total na percepção e na cognição humana, propiciando uma construção interdisciplinar.

No intuito de aderir a novas estratégias didáticas lúdicas, para compreensão de assuntos voltados à morfofisiologia das células, objetivou-se com esse trabalho relatar a experiência vivida em séries do $1^{\circ}$ ano do Ensino Médio na disciplina de biologia, utilizando essas 
metodologias alternativas como os jogos de citologia e a paródia musical, para compreensão de termos e conceitos novos considerados pelos alunos como difíceis de serem memorizados.

\section{METODOLOGIA}

As estratégias utilizadas para transmitir os conhecimentos e fixação dos conteúdos foram os jogos (palavras cruzadas) e também o uso de paródia musical, ambos voltados para a biologia celular. A utilização desses procedimentos metodológicos foram aplicados nas turmas do $1^{\circ}$ ano do Ensino Médio da EREM Frei Epifânio, no Município de São Joaquim do MontePE.

Diante da proposta de desenvolvimento, foi perceptível que havia a necessidade de escolher novos métodos de aprendizagem, para facilitar a memorização de alguns conceitos tão importantes em citologia, bem como também despertar o interesse do aluno pela área. Os conteúdos conceituais referentes a tipos, estruturas e funções das células foram pesquisados em Favaretto (2013), livro didático do educando e também em site educativo como TodaBiologia. Os tópicos abordados durante o jogo de palavras cruzadas foram tipos e organelas celulares, como: os lisossomos, complexo golgiense, REL, RER, cloroplastos, vacúolos, ribossomos, membrana plasmática entre outras. As comparações entre células procariontes e eucariontes e as funções de suas estruturas foram incluídas na paródia musical.

Os conteúdos que foram abordados tanto nas palavras cruzadas quanto na paródia, desafiaram os alunos a pensar e memorizar o assunto em questão. A paródia musical foi considerada como um momento de aprendizagem mais descontraído, pois a mesma mostrou os conteúdos de uma forma lúdica diferenciada onde foi observada uma maior interação entre os alunos.

As turmas envolvidas nesse trabalho foram divididas em dois grupos, cada equipe dispunha de fichas com palavras cruzadas diferentes, todas obedecendo ao mesmo grau de complexidade. O primeiro grupo a terminar as palavras cruzadas venceu a disputa e apresentou para o restante da turma as respostas que os mesmos encontraram. Após o grupo vencedor apresentar as respostas encontradas nas palavras cruzadas, foi iniciado um debate para que esses conteúdos pudessem ser apreendidos.

Em seguida, foi trabalhada a paródia musical, abordando conceitos e fazendo uma analogia entre células procarióticas e eucarióticas e funções de suas estruturas. Foram utilizados recursos de mídia como data show com slides para melhor visualização da letra e também instrumentos musicais da própria escola, como violão e pandeiro.

\section{RESULTADOS E DISCUSSÃO}

O trabalho desenvolvido permitiu aos discentes das turmas do $1^{\circ}$ ano do Ensino Médio da EREM Frei Epifânio um maior aprofundamento dos conteúdos de biologia celular, e ao mesmo tempo um maior entusiasmo pelas aulas que os mesmos julgavam "chatas". A utilização de outras metodologias foi de suma importância para a apreensão desses conteúdos de maneira diferenciada daquela que os discentes estavam acostumados.

O uso dos jogos, como palavras cruzadas e a paródia, transmitiram informações bem atrativas despertando a vontade do discente em querer aprender. Nesse sentido D’Oliveira e Medeiros (2006) citam que assuntos considerados pesados e complexos, pelos alunos, tornam-se abrandados através de músicas parodiadas. Quando o aluno percebe o que esta sendo dito, ele se sente motivado a aprender mais, ousa mais e pergunta mais. Ele estará determinado a buscar novos conhecimentos e em consequência disso se tornará um aluno melhor.

Através desses métodos de ensino, foi constatado que os alunos tornaram-se mais participativos, uma vez que os mesmos ficavam dispersos nas aulas que possuíam caráter nada motivador. Sendo a motivação um dos fatores principais que influenciam no processo de aprendizagem. Nesse contexto, houve uma aprendizagem totalmente criativa pelo uso da paródia e dos jogos. Segundo Kneller (1978), para aprender de maneira criativa, o aluno há de 
combinar o conhecimento que adquire numa determinada lição com aqueles retirados de outras áreas da experiência.

\section{CONSIDERAÇÕES FINAIS}

Quando se há um caráter inovador nas aulas, as mesmas se tornam atrativas e despertam o prazer pelo processo de aprendizagem, que na maioria das vezes é bastante desmotivador, principalmente quando o método de transmissão é tradicional. Nesse contexto, é importante que as práticas educativas sirvam de estímulos para os alunos, e que os mesmos sintam-se encorajados de fazer uso desses novos métodos para utilizarem como ferramentas de aprendizagem. Uma vez que a utilização dessas atividades lúdicas por meios de jogos e paródias despertam uma curiosidade maior pelo conteúdo e também gera na própria sala de aula momentos de descontração.

Sendo assim, fica-se evidente a importância dessa pedagogia de ensino para que professores formados e em formação possam aderir em sua prática pedagógica. Visto que, esses métodos servirão para construção de conhecimentos e também para uma melhor interação professor-aluno, permitindo uma participação mais ampla do discente nas aulas de Biologia.

\section{REFERÊNCIAS}

D’OLIVEIRA, R. G.; MEDEIROS, M. A. A. Métodos lúdicos aplicados ao ensino da Biologia. In: ENCONTRO REGIONAL DE ENSINO DE BIOLOGIA, 2, João Pessoa-PB. Anais...EREBIO-NE, 2006.

FAVARETTO, J. A. Biologia unidade e diversidade. 1. ed. São Paulo: Saraiva, 2013. v. 1.

FORTUNA, T. R. O brincar, as diferenças, a inclusão e a transformação social. Atos de Pesquisa em Educação, Blumenau, v. 3, n. 3, p. 460-472, 2008.

KISHIMOTO, T. M. O jogo e a educação infantil. São Paulo: Pioneira, 1999.

KNELLER, G. F. Arte e ciência da criatividade. São Paulo: Ibrasa, 1978.

NARDELLI, J. Música: a escola que canta, encanta. Itajaí: Universidade para o Desenvolvimento do Alto vale do Itajaí, 2000. (Monografia de Curso de Especialização).

SANTANA, A. C. D.; MONTENEGRO, A. K. A.; SANTOS, D. P. N.; ABILIO, F. J. P. Ensino de Ciências na Educação Infantil e Ensino Fundamental: inovações metodológicas no Curso de Pedagogia da UFPB. ENCONTRO REGIONAL DE ENSINO DE BIOLOGIA, 2, João PessoaPB. Anais... EREBIO-NE, 2006.

TEIXEIRA, M. F. Fundamentos teóricos que envolvem a concepção de conceitos científicos na construção do conhecimento das ciências naturais. ENCONTRO REGIONAL DE ENSINO DE BIOLOGIA, 2, João Pessoa-PB. Anais... EREBIO-NE, 2006.

TODA BIOLOGIA. Organelas celulares e suas funções. Disponível em: $<$ http://www.todabiologia.com/citologia/organelas_celulares.htm>. Acesso: 10 de Abril de 2016.

URIARTE, M. Z. Música e escola: um diálogo com a diversidade. Educar, Curitiba, v. 24: p. 245-258, 2004. 